\title{
CONSTRUCTION OF A GROWTH MODEL TO PREDICT THE INDIVIDUAL STEM VOLUME OF Eucalyptus grandis HILL EX MAIDEN (TOOLUR) IN SRI LANKA
}

\author{
S.M.C.U.P.P. Subasinghie \\ Department of For \&stry \& Environmental Science, \\ University of Sri Jayewardenepura
}

Toolur (Eucalyptus grandis Hill ex Maiden) belongs to farnily Myrtaccae las been planted widely in the hill country of Sri Lanka for high quality timber and fuel wood. For the present study a growth model was constructed to predict the total stem volume of individual toolur trecs. Data were obtained using tempotally sampled plots from the tree plantations in Badulla forest division and $\sigma$ plantations in Nuwara-Eliya forest division.

Data were first partitioned according to the quality of the sitc. An index developed using a top height / plantation age was used for site classification and three significantly different sites could be identified. In order to construct the model, $75 \%$ of sample plots from each plantation was used and the rest was reserved for the purpose of validating the constructed model with independent data.

The basic model structure was devcloped using the relationship between volume and form factor, basal area and total height. Form factor is difficult to measure because it varies with age, site quality, density etc. even for the same species. Therefore kecping the other two variables, it was tried to replace the form factor using other explanatory variables, which can be measured casily.

All possible combinations of the explanatory variables were tested in order to obtain the best models. The performance of the mocies was observed using statistical tests and standard residual distributions. For the sclecied models, the intercept was not significantly different from zero and number of trees per hectare and total basal area tested to represent the stand density was also not significant.

After selecting the four suitable models at the first stage, the possibility of using one set of parameters instead of separate parameters scts for different site types was tested. First the parameters were estimated for the pooled data. Using the resulted nodels, normal residuals were calculated separately for three site types. Then the significance of the residuals was tested using analysis of variance for select the final model with common set of parameters. A selected model contained basal area and totat height of individual trees and a site quality factor as explanatory variables. It was then compared directly with the particular observed values. After all the tests, the results jndicatcd that the model constructed in this study proved its strength on predicting the total volume of individual stems precisely because it indicated a very low bias and a high modeling efficiency of over 0.09 .

The resultant model which can be used to predict the individual toolur stem volume for all site types is:

$(\text { Volume })^{1 / 2}=0.5946 *$ (basal area $*$ total height $)^{1 / 2}+0.0356 *$ (total basal area / top height $)$.

Proceedings of the Eighth Annual Forestry and Environment Symposium 2002 of the Department of Forestry and Environmental Science. University of Sri Jayewardenepura, Sri Lanka 